\title{
The Pathogenesis of Pulmonary Lymphangioleiomyomatosis: A State of Neoplastic Senescence
}

\author{
Charles Michael Lombard ${ }^{1,2}$ \\ ${ }^{1}$ Department of Pathology, Stanford University School of Medicine, Stanford, California, the United States \\ ${ }^{2}$ Department of Pathology, El Camino Hospital, Mountain View, California, the United States
}

Email address:

charles_lombard@elcaminohospital.org

\section{To cite this article:}

Charles Michael Lombard. The Pathogenesis of Pulmonary Lymphangioleiomyomatosis: A State of Neoplastic Senescence. International Journal of Clinical and Experimental Medical Sciences. Vol. 6, No. 6, 2020, pp. 136-148. doi: 10.11648/j.ijcems.20200606.16

Received: October 28, 2020; Accepted: November 19, 2020; Published: November 30, 2020

\begin{abstract}
A novel pathogenesis of pulmonary lymphangioleiomyomatosis (PLAM) is presented incorporating a review of clinical and pathology research on the disease together with a review of research in the field of senescence. In this model of pathogenesis it is proposed that: 1) the primary site of origin for this disease is the Mullerian smooth muscle found in the female reproductive tract and this accounts for the striking female predominance of the disease; 2) the tumor spreads to the lungs via a mechanism similar to lymphangitic carcinomatosis and this accounts for its universal symmetric and bilateral distribution; 3) there is a mutational basis for a senescence-associated growth arrest which helps explain the absence of enlarging tumor masses in the lung despite years of disease duration; and 4) PLAM cells have a senescence-associated secretory phenotype with implications for the pathogenesis of the cystic transformation of the lungs. The secretory phenotype of PLAM cells is reviewed and the overlap with the senescence associated secretory phenotype products of known senescent cells is documented. The role of the switch to glycolytic metabolism (Warburg state) by PLAM cells is described. Finally, the "contradictory signals" hypothesis for the induction of the senescent state is explored and its role in PLAM described.
\end{abstract}

Keywords: Pulmonary Lymphangioleiomyomatosis, Senescence-associated Secretory Phenotype, Senescence-associated Growth Arrest, Pathology, Pathogenesis

\section{Introduction}

Pulmonary lymphangioleiomyomatosis (PLAM) is an enigmatic disease. The disease occurs sporadically and also in patients with the tuberous sclerosis complex (TSC). In many ways the disease presents clinically and radiographically like chronic interstitial lung disease. [1] The cystic transformation seen in the lungs resembles cystic change seen in a variety of chronic interstitial lung diseases, including Langerhans' cell granulomatosis and lymphoid interstitial pneumonia. The slow progressive destruction of the lungs is also similar to progressive cases of these interstitial lung diseases. However, it has been demonstrated that PLAM is a clonal neoplastic process. [2] PLAM as a neoplastic process has unusual characteristics. The universal bilateral distribution of this neoplasm in the lung is consistent with a metastatic process to the lung. However, for many years, a primary site for these metastases has remained obscure and, as noted above, the clinical and radiographic progression of PLAM more closely resembles a progressive chronic interstitial pneumonia rather than a metastatic neoplasm. The median transplant free survival from the onset of symptoms, without therapy, is 29 years. [3] Furthermore, over the prolonged clinical course of this disease, enlarging tumor masses do not appear in the lungs, as one might expect with metastases.

In this review I propose the pathogenesis of PLAM is best understood using a model of pulmonary lymphangitic carcinomatosis. Furthermore, the primary site of tumor with subsequent spread to the lungs will be proposed to be the Mullerian smooth muscle neoplasms of the female genital tract with myomelanocytic differentiation. Pathologic progression of the disease in the lungs will be discussed in detail and reasons for the absence of tumor mass formation 
explored, including the proposal that LAM represents an unusual state that can be characterized as a state of "neoplastic senescence". [4]

\section{The Primary Site for the Metastatic Neoplasm PLAM is Mullerian Smooth Muscle}

Clues to the site of origin of the metastasizing neoplasm leading to PLAM were present early on. This has always been a disease predominately affecting women of child bearing age. As such, the female genital tract has been considered a possible primary site. [2, 5, 6] Renal AML which is found in $>80 \%$ of patients with PLAM associated with tuberous sclerosis has also been a suggested primary site. There is evidence that essentially eliminates renal AML as a primary site for PLAM in a following section. It is well documented that in PLAM there is lymph node involvement from the pelvic lymph nodes up through the retroperitoneal chain and into the mediastinal lymph nodes. [7-10] A landmark study with examination of surgical pathology specimens from the female genital tract in patients with PLAM identified LAM lesions in the Mullerian smooth muscle of the uterus, fallopian tube, broad ligament, and ovary. [11] These altered smooth muscle proliferations show the characteristic myomelanocytic differentiation seen in LAM cells with smooth muscle marker desmin as well as melanocytic marker HMB-45. In these myomelanocytic proliferations associated with PLAM there is also a striking associated lymphovascular proliferation. In addition, intralymphatic LAM cells are identified in these cases. The related condition of incidental nodal LAM has also been studied and lends further support to the concept of Mullerian smooth muscle as the cell of origin for LAM. Precursor lesions for these incidental nodal LAM lesions have been described and evidence given that these arise from myometrial smooth muscle cells. [12] (Figure 1) Unlike the typical uterine LAM lesions seen in association with patient's suffering from PLAM, the precursor LAM lesions lack the pronounced lymphatic proliferation seen with the uterine LAM lesions associated with PLAM. (Figure 2) Although it is generally thought that incidental nodal LAM is not a harbinger of PLAM, [13] there are reasons to question this conclusion. First, there is a well-documented case of incidental nodal LAM progressing to PLAM. [14] Second, PLAM is a very slowly progressive disease and follow up in reported series of nodal LAM are quite limited. (Table 1) Evidence that incidental nodal LAM represents spread from the uterus is supported in two ways. First, incidental nodal LAM has not been described men. 716 Prostatic carcinoma resection specimens with pelvic lymph node dissections reviewed at this institution revealed $0 / 716$ cases with pelvic lymph nodes involved by incidental nodal LAM. In women undergoing pelvic lymph node biopsies as a staging procedure for a variety of gynecologic neoplasms, the incidence of incidental nodal LAM at this institution was $0.73 \%$ (7/953 cases) [9] which is remarkably similar to the incidence reported at another institution of $0.46 \%$. [14] Second, when incidental nodal LAM is detected, in all cases the pelvic lymph nodes are involved, and in a subset of these cases there is also para-aortic lymph node involvement. There are no cases of para-aortic lymph node involvement without pelvic lymph node involvement, confirming the stepwise progression of spread from uterus to pelvic lymph nodes to para-aortic lymph nodes. [12-15]

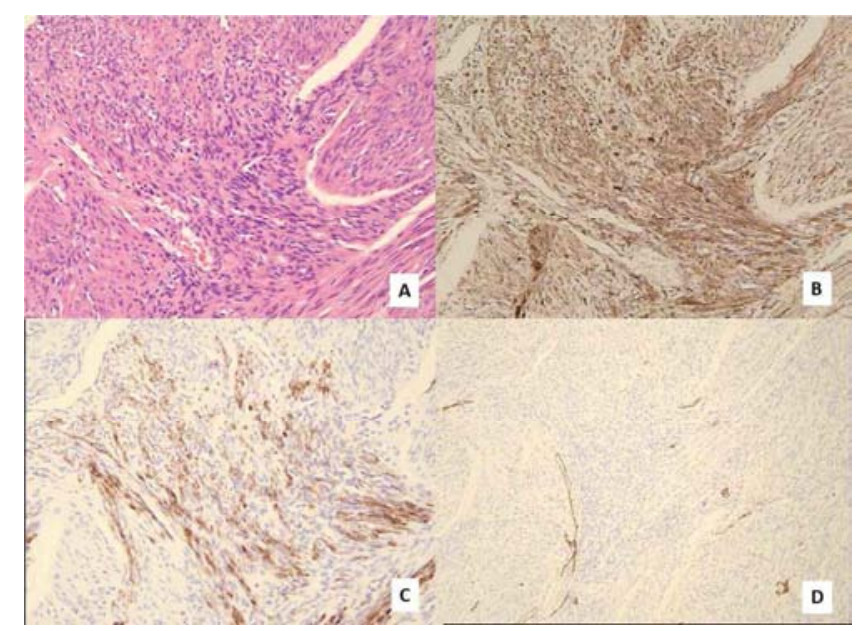

Figure 1. Precursor LAM lesion in uterus of patient with incidental nodal LAM. Note that the cells comprising these lesions are virtually indistinguishable from the surrounding Mullerian myometrial smooth muscle cells on routine $H / E$ stains. The lesion is not identifiable on gross examination of the uterus. (A) Cathepsin K IHC stain shows strong positive staining of the precursor LAM lesion. (B) HMB-45 IHC stain shows strong positive staining of the precursor LAM lesion. (C) D2-40 IHC stain shows absence of an associated lymphovascular proliferation. $€$ All images at $200 x$ magnification.

Table 1. Incidental Nodal LAM.

\begin{tabular}{|c|c|c|c|c|}
\hline \multicolumn{5}{|c|}{ Incidental Nodal LAM } \\
\hline \multicolumn{5}{|c|}{ Incidence in Female pelvic lymph nodes: } \\
\hline \multicolumn{4}{|c|}{ Series from ECH [12] } & $0.73 \%$ \\
\hline \multicolumn{4}{|c|}{ Series from NCCH Tokyo [14] } & $0.46 \%$ \\
\hline \multicolumn{4}{|c|}{ Incidence in Male pelvic lymph nodes ECH } & $\mathbf{0 \%}$ \\
\hline \multicolumn{5}{|c|}{ Studies with follow up of incidental nodal LAM: } \\
\hline Institution & \# patient & Median (mean) f/u & \# PLAM & Time to PLAM \\
\hline $\mathrm{UCSF}[15]$ & 26 & $18(\mathrm{~N} / \mathrm{A}) \mathrm{mo}$ & 0 & $\mathrm{~N} / \mathrm{A}$ \\
\hline NCCHTokyo [14] & 8 & $30(45) \mathrm{mo}$ & 1 & $86 \mathrm{mo}$ \\
\hline
\end{tabular}




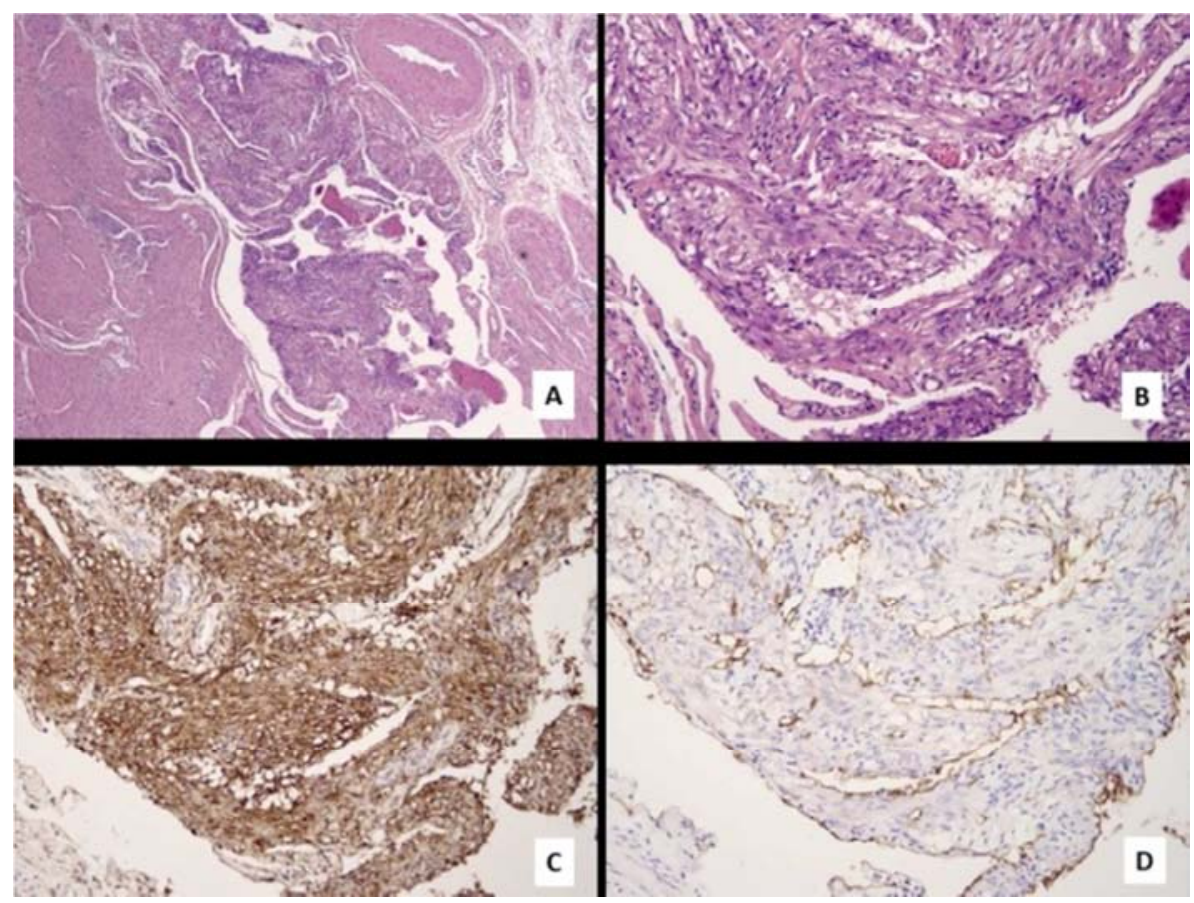

Figure 2. Uterine LAM lesion in patient with TSC and PLAM. (A) Uterine lesion is clearly demarcated from surrounding myometrium on routine H/E stain. This lesion was grossly visible on examination of the uterus. (40 x magnification) (B) Cytologic features of uterine LAM lesion showing no significant nuclear atypia and no significant mitotic activity. (200 x magnification) (C) Cathepsin K IHC stain shows strong positive staining of uterine LAM lesion. (200 $x$ magnification) (D) D2-40 IHC stain shows positive staining of LAM-associated lymphovascular proliferation. (200 x magnification)

\section{Mullerian Remnants Account for the Rare Cases of Men with PLAM}

Even within the population patients with the TSC it is rare for a male to develop histologically documented PLAM. Nevertheless, there are well-documented cases. [16, 17] Mullerian remnants are well-documented in male patients. [18] When Mullerian remnants can be found in male patients they are typically small and infrequent. However, with a TSC germline mutation already in place, a second hit mutation in these rare pelvic Mullerian remnants could give rise to a precursor LAM lesion in the associated Mullerian smooth muscle, progress to well-developed LAM lesions, and spread through lymphatics to pelvic lymph nodes, up the retroperitoneal chain, into the lungs. Admittedly, at this time this is conjectural and without evidence. If an autopsy were performed on a male patient with PLAM one would have to look closely at sites where ectopic Mullerian remnants are most commonly found in order to detect small precursor lesions similar to those found in the female genital tract of patients with PLAM. The lesions are frequently microscopic and can be easily overlooked without a focused examination.

\section{Renal AML Is Associated with PLAM But it is Not the Neoplasm That Spreads to the Lung Causing PLAM}

Although renal AML is found in $>80 \%$ of the TSC- associated PLAM and $30-50 \%$ of cases of sporadic PLAM [19] there are reasons why this neoplasm is not the primary site/origin for the metastasizing neoplasm PLAM.

First, the morphology of renal AML is distinctly different from PLAM. Renal AML as a mixed spindle and epithelioid myomelanocytic proliferation admixed with fat and blood vessels. The vascular proliferation is hemangiomatous and not lymphatic vascular proliferation. Renal AML does not have the limited growth potential that is seen in cases of PLAM. Renal AML has the expected growth pattern of typical neoplastic processes with progressive enlargement and formation of macroscopic gross tumors. Second, renal AML rarely spreads to regional lymph nodes, and when it does it is accompanied by the fatty proliferation. PLAM on the other hand never has a fatty component. Nodal involvement in PLAM is characterized by the myomelanocytic cell proliferation and unlike renal AML nodal involvement in PLAM is associated with a marked lymphatic proliferation. Thirdly, renal AML is not nearly as restricted to female patient as PLAM. If renal AML were a precursor lesion for PLAM one would expect a significantly higher rate of PLAM in men. In our hospital the F:M ratio for renal AML is 3:1 and 2:1 in the literature. [20] The F:M ration for PLAM is $>100: 1$. [16, 17] In summary, the morphology of the renal AML lesion and the morphology of the rare cases of spread to regional lymph nodes is unlike that of lesions of the LAM, and in addition, the F:M ratio of renal AML is very different from that of PLAM. The distinguishing features of renal AML vs. LAM are summarized in Table 2. Figure 3 shows examples of the differing appearances of renal AML vs. LAM involvement of 
lymph nodes.

Table 2. Comparison of Renal AML and PLAM.

\begin{tabular}{lll}
\hline Comparison of: & Renal AML & Pulmonary LAM \\
\hline Gross appearance & Enlarging macroscopic mass lesions & Microscopic lesions with limited growth potential \\
Microscopic composition of tumor & Specialized myomelanocytic cells, fat, blood & Specialized myomelanocytic cells, no fat, no blood \\
Accompanying vascular proliferation & vessels & vessels \\
F:M ratio & Hemangiomatous & Lymphovascualr \\
\hline
\end{tabular}

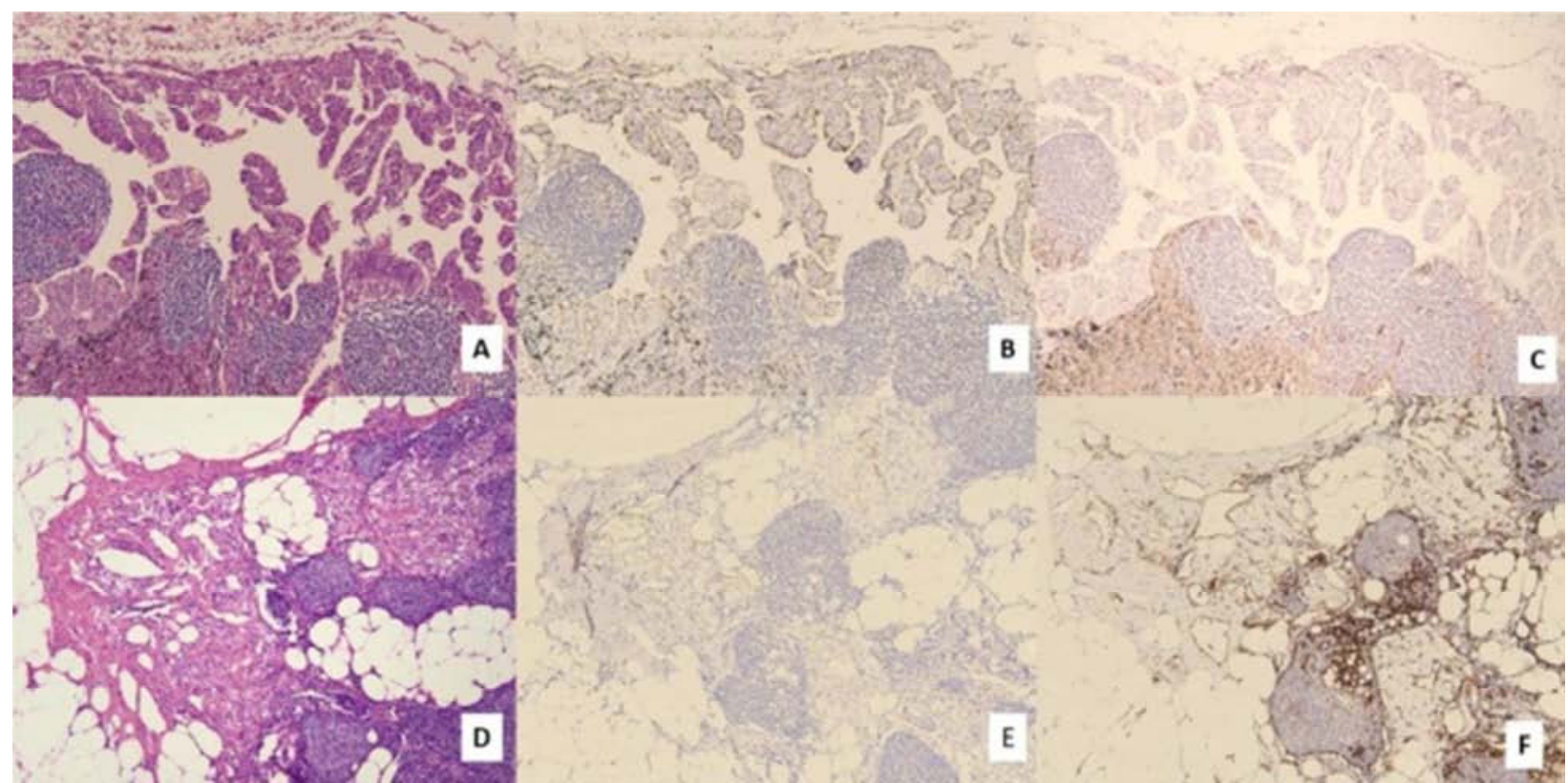

Figure 3. Comparison of lymph node involvement in PLAM and renal angiomyolipoma. (A) Pulmonary hilar lymph node involved by LAM. Note absence of associated fatty proliferation. (B) D2-40 IHC stain of hilar lymph node with LAM shows positive staining of associated lymphovascular proliferation. (C) CD 31 IHC stain of hilar lymph node with LAM shows attenuated/absent staining of vascular proliferation, consistent with a lymphatic proliferation. (D) Paraaortic lymph node with involvement by renal angiomyolipoma. Note the associated fatty proliferation. (E) D2-40 IHC stain of para-aortic lymph node with involvement by renal angiomyolipoma shows an absence of staining providing evidence for a lack of an associated lymphovascular proliferation. $(F) C D 31$ IHC stain of para-aortic lymph node with involvement by renal angiomyolipoma shows strong positive staining of vascular proliferation consistent with an associated hemangiomatous vascular proliferation. All images at $100 \times$ magnification.

\section{PLAM Is a Neoplastic Process in a Senescent State}

Possibly the most perplexing question in the pathogenesis of PLAM relates to this apparent paradox. It is remarkable that a neoplastic process can progresses over decades of duration without the formation of enlarging tumor masses to the point where they are clearly recognizable as macroscopic neoplastic proliferative mass lesions. I have previously proposed a solution to this enigma. [4] The clues to the solution lie in an examination of the molecular pathogenesis of LAM. There are mutations to mTOR in both TSCassociated LAM and sporadic LAM. [21] The mTOR pathway and entire cascade of cellular mechanisms involves a broad range of controls on cellular homeostasis and proliferation. Remarkably, when one examines the pathways involved in cellular senescence, one sees an intriguing overlap of these cellular pathways. [22] Cellular senescence has 2 important related but separate characteristics. The first is a cell cycle arrest. Although initially this arrest was thought to be stable and permanent, it is now recognized that there is significant flexibility in this senescence-associated growth arrest such that the senescent cells are able to enter $\mathrm{G}$ phase activity on a limited basis. [23] This is an important feature to recognize regarding the pathogenesis of LAM.

For many years the "Warburg" phenomenon whereby senescent cells differ from normal cells by increased metabolism of glucose by glycolysis has been recognized. Increased metabolism of glucose by glycolysis has been documented in LAM cells. [24] MTORC1 activation promotes a shift in glucose metabolism from oxidative phosphorylation to glycolysis by increasing translation of HIF1a which subsequently drives expression of glycolytic enzymes. [25] Furthermore, there is a depletion of lysosomes that appears to be mediated by MTOC1 inhibition of TFEB, which controls lysosome and autophagy-specific genes. [26] In addition, MTORC1 mediated inhibitory phosphorylation of autophagy initiating kinase ULK1, and inhibitory phosphorylation of ATG14, a component of PIK3C 3 which is required for autophagosome maturation also contributes to lysosomal dysfunction. [26] There is also evidence that ubiquitization and degradation of autophagy-lysosomal pathway protein LC3 and lysosomal membrane associated 
proteins 1 and 2 further contribute to lysosomal dysfunction in the TSC. [27] This lysosome depletion further limits the capacity for glucose metabolism by oxidative phosphorylation. Senescence associated cell cycle arrest is thought to be driven by mTOR activation associated cell proliferation signals in the presence of cell cycle inhibitors P53, P16, and pRB. This "contradictory" signaling is thought to be an important factor in driving cells into senescenceassociated growth arrest. $[23,28]$ In TSC, mutations to the TSC1/2 complex result in Rheb activation, which leads to mTORC1 activation. [29] MTORC1 activation, in addition to induction of the Warburg state, has two additional and conflicting manifestations.

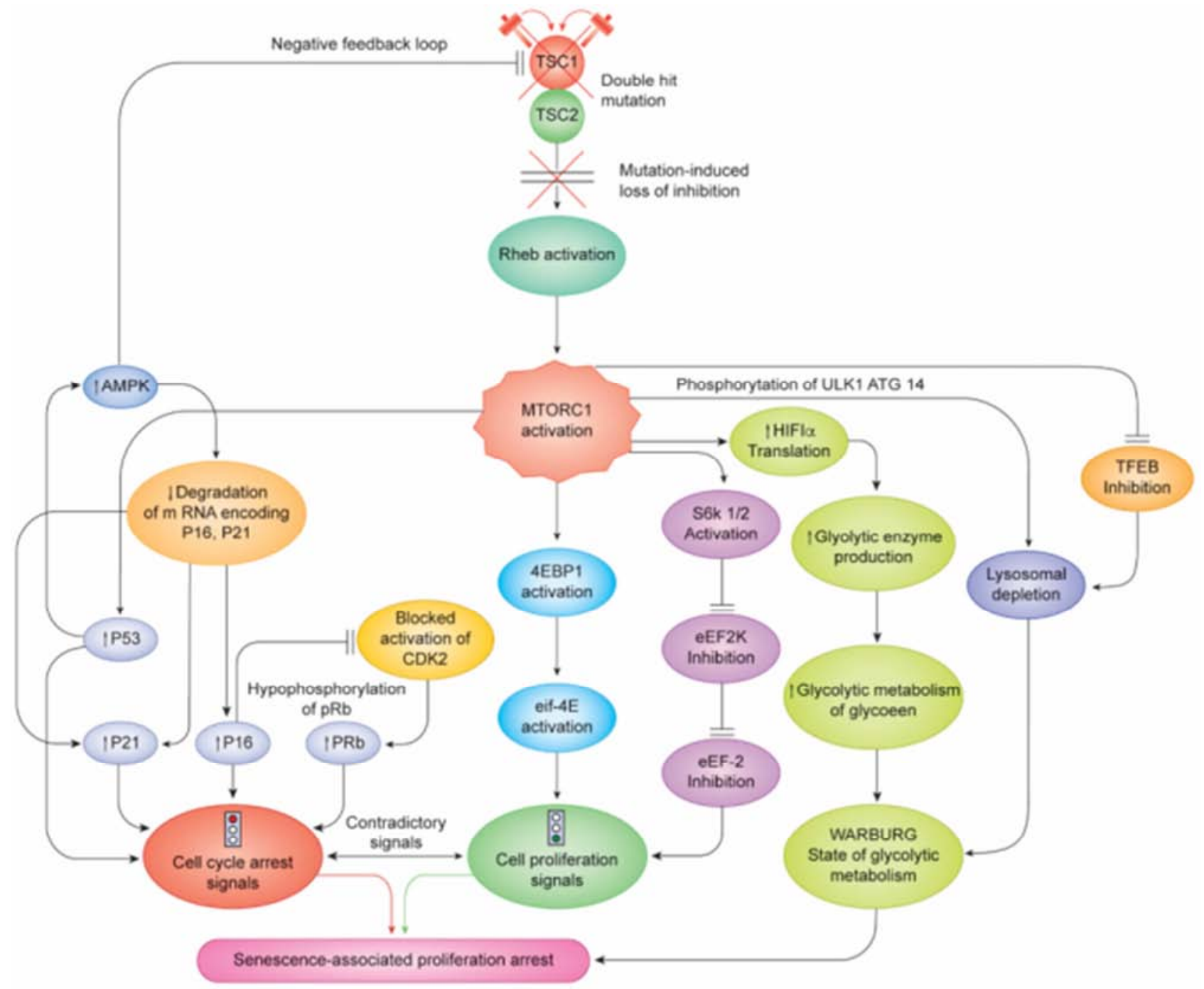

Figure 4. Pathways for senescence-associated proliferation arrest. There are 3 components to this cascade: (A) The establishment of the Warburg state of glycolytic metabolism. (B) And the two conflicting cell cycle signals: (1) Cell cycle arrest signals through activation/increased expression of P16, P21, P53, and pRb, (2) Cell proliferation signals through S6Kand $4 E B P 1$ activation.

First, there is a growth arrest cascade with P53 activation and overexpression. [30] P53, in turn, activates and leads to overexpression of cell cycle inhibitor P21. [24] In addition, P53 activation, as part of a negative feedback loop leads to increased activity of the AMPK pathway. One arm of this pathway results in $\mathrm{Hu}$ antigen R-dependent degradation of the mRNA encoding tumor suppressors P16 and P21. [31] $\mathrm{P} 16$, in addition to direct cell cycle arrest signals, also blocks activation of CDX2 which leads to activating hypophosphorylation of $\mathrm{pRb}$, another growth arrest signal. [32] In summary, MTORC1 activation leads to overexpression of 3 proteins associated with cell cycle arrest, tumor suppressor P53, P21 cyclin-dependent kinase inhibitor 1, and P16 cyclin-dependent kinase inhibitor $2 \mathrm{~A}$.

Second, MTORC1 activation also generates contradictory cell proliferation signals through two routes. First MTORC1 phosphorylates 4EBP1 triggering its release from eiF4E stimulating cap-dependent translation and production of cell proliferation signals. [31] A second pathway involves MTORC1 phosphorylation and activation of S6K1/2 with subsequent downstream phosphorylation and inactivation of eEF2K and eEF2 which lead to translation of further cell proliferation signals. $[31,33]$ The cumulative effects of these contradictory signaling pathways, together with the Warburg 
state, result in the senescence-associated cell cycle arrest (Figure 4).

Although cell growth arrest is the best known feature of senescence, a second feature of the senescent cell is that they have a characteristic senescence associated secretory phenotype (SASP). [34] The array of secretory products varies depending on cell type undergoing senescence, however, secretion of tissue matrix metalloproteinases and VEGF are well described and consistent components of this secretory phenotype. This second feature of the senescent cell, the SASP is also explained by the TSC-associated mutations to the mTOR complex. Activated mTOR increases translation of subsets of mRNA including mRNA encoding IL-1 alpha. [35] Through binding to IL- $1 \alpha \mathrm{R}$ there is stimulation of NFKB signaling leading to the subsequent transcription of multiple cytokine SASP related genes. In addition to the increased transcription of SASP- associated cytokines, there is evidence that mTOR activation also leads to increased stability of these NFKB driven transcripts via increased transcription of MK 2. [36] MK2 activity results in the phosphorylation of the mRNA binding and destabilizing protein ZFP36L1. The cumulative result of the loss of this destabilizing protein, combined with increased transcription of SASP-associated cytokines is a stable, increased production of SASP- related cytokines. (Figure 5) Table 3 shows a list of SASP related cytokines and the evidence that these are overexpressed in LAM.

I have not included the serine protease cathepsin $\mathrm{K}$ in the list of SASP products. Cathepsin B has been identified as a SASP product, [34] however, to my knowledge, cathepsin K has not been identified as such. Nevertheless, there is emerging evidence that cathepsin $\mathrm{K}$ is involved in senescence processes and I believe it will be identified as an SASP product. In experimental animal models with cathepsin $\mathrm{K}$ knock-out mice it has been noted that cellular senescence markers P53, P16, and P21 were all significantly lower in the cathepsin $\mathrm{K}$ knock-out mice as compared to wild type mice. $[37,38]$ In addition, in one of these models, a mouse model for pycnodysostosis, it was noted that forced expression of cathepsin K induced premature senescence. [37]

In summary I've proposed that LAM represents an unusual neoplastic condition which I have characterized as a state of "neoplastic senescence". This does not represent oncogene driven senescence, but rather a metabolic senescence driven by the mutations to the mTOR complex with subsequent alterations of function in mTORC1 pathways. This is not a comprehensive review of cellular senescence pathways as there are other pathways involved, including the polycomb protein CBX7-Integrin beta 3 pathway. [39] Rather, I have presented pathways demonstrating the role of important senescence associated pathways clearly controlled by mTOR that provide evidence for the concept that PLAM represents a state of "neoplastic senescence". Adoption of this model facilitates understanding of the unusual manifestations and biologic behavior of PLAM.

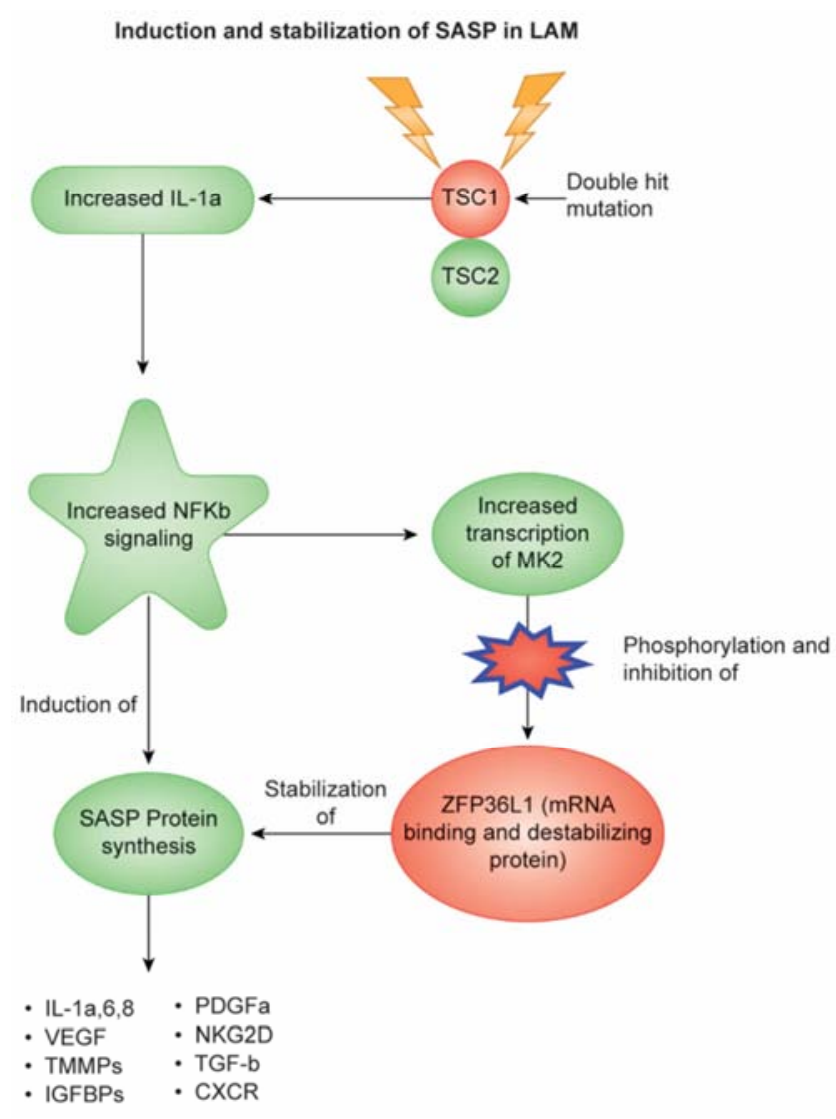

Figure 5. Pathway for the induction and stabilization of the SASP in PLAM. Mutation to the TSC complex leads to loss of inhibiting signals and increased expression of $I L-1 \alpha$ leading to NFK $\beta$ activation and increased protein synthesis.

\section{LAM Cells Spread to the Lung in a Uniform, Bilateral and Symmetric Distribution}

As noted above, the neoplastic LAM cells which arise from the Mullerian smooth muscle cells and subsequently spreads to regional lymph nodes through lymphatic spaces, the production of which are stimulated and induced by the SASP cytokine VEGF. Spread continues up the retroperitoneal chain of lymphatics to the thoracic duct. At this point the LAM cells have access to the blood circulation through the subclavian vein. LAM cells have been detected in the circulation of patients with PLAM. [40] Although one can consider the possibility of hematogenous dissemination of LAM cells to the lungs, there are a number of reasons why this is not the case. While blood born metastatic disease to the lung is frequently bilateral, and it can occasionally be somewhat symmetric, in the vast majority of cases there is a significant discrepancy between right and left lung involvement in blood borne metastatic disease. In marked contrast, disease involvement in PLAM has a consistent diffuse, bilateral and symmetric involvement of the lungs (Figure 6). Secondly, if this were blood borne metastatic disease one would anticipate a high incidence of metastatic deposits in other sites favored by blood born metastases, including brain, bone, and liver. These 
systemic metastases are consistently absent in patients with PLAM. Third, blood born metastasis does not explain the propensity of PLAM to be associated with chylothorax and pneumothorax. Finally, blood born metastases do not explain the distinct histologic lymphatic pattern of distribution seen in some cases of PLAM. The reason LAM cells circulating in the peripheral blood fail to successfully metastasize is not entirely clear. LAM cells are clearly lymphotrophic and capable of spread and growth in lymphatic spaces. The composition of lymphatic fluid is quite different from blood and I propose that lymphatic fluid contains stimulatory factors for LAM cells, including VEGF at high concentrations as well as other, as yet undiscovered/uncharacterized stimulatory factors, that are absent from blood in similar concentrations. In blood, it appears the circulating LAM cells are likely terminal senescent cells and are culled out of circulation, destroyed, and do not have the ability to implant into tissues, resume growth, and cause metastatic deposits given the absence of systemic metastases of LAM lesions in patients with PLAM.

Table 3. Senescence associated secretory products and evidence for production by LAM cells.

\begin{tabular}{|c|c|c|}
\hline Selected SASP-related products & Representative functions of products & Evidence for association with LAM cells \\
\hline Interleukin-1 $\alpha[34,54]$ & $\begin{array}{l}\text { Cytokine associated with immune induced } \\
\text { inflammatory reactions }\end{array}$ & $\begin{array}{l}\text { Increased secretion by LAM cells in biochemical assay } \\
{[55]}\end{array}$ \\
\hline Interleukin-6 $[54,56,57]$ & $\begin{array}{l}\text { Cytokine associated with inducing differentiation in B } \\
\text { cells to Ig secreting cells }\end{array}$ & $\begin{array}{l}\text { Increased secretion by LAM cells in biochemical assay } \\
\text { [55] }\end{array}$ \\
\hline Interleukin-8 $[34,54,56]$ & Cytokine mediator of innate immune response & $\begin{array}{l}\text { Increased secretion by LAM cells in biochemical assay } \\
{[55]}\end{array}$ \\
\hline CXCR [57] & $\begin{array}{l}\text { Chemokine receptor for CXCL-12 chemoattractant for } \\
\text { lymphocytes; Increased expression in cancer? related to } \\
\text { metastasis }\end{array}$ & $\begin{array}{l}\text { CXCR4 positive immunohistochemical staining of LAM } \\
\text { cells [58] }\end{array}$ \\
\hline $\begin{array}{l}\text { Insulin Growth Factor Binding } \\
\text { Proteins (IGFBP) }[34,54]\end{array}$ & $\begin{array}{l}\text { Growth factors involved in cell growth and } \\
\text { differentiation }\end{array}$ & $\begin{array}{l}\text { IGFBP positive immunohistochemical staining of LAM } \\
\text { cells [59] }\end{array}$ \\
\hline VEGF $[35,39]$ & $\begin{array}{l}\text { Endothelial growth factor; stimulates } \\
\text { lymphangiogenesis }\end{array}$ & $\begin{array}{l}\text { VEGF positive immunohistochemical staining of LAM } \\
\text { cells }[60,61] \\
\text { Increased serum VEGF levels in patients with LAM [62] }\end{array}$ \\
\hline TGF- $\beta[56,57]$ & $\begin{array}{l}\text { Cytokine associated with activating transcription of } \\
\text { wide range of proteins related to cell growth and } \\
\text { differentiation; may assist in induction of senescence }\end{array}$ & $\begin{array}{l}\text { TGF- } \beta \text { positive immunohistochemical staining of LAM } \\
\text { cells }[63]\end{array}$ \\
\hline PDGFA $[35,54]$ & $\begin{array}{l}\text { Protein which on binding to PDGF receptors is } \\
\text { stimulatory for angiogenesis, cell growth and } \\
\text { differentiation }\end{array}$ & $\begin{array}{l}\text { PDGFR- } \alpha \text { positive immunohistochemical staining of } \\
\text { LAM cells [61] }\end{array}$ \\
\hline NKG2D [64] & NK cell detectable and activating ligand & $\begin{array}{l}\text { NKG2D positive immunohistochemical staining of LAM } \\
\text { cells [65] }\end{array}$ \\
\hline TMMP 2, $9[34,54,56,57]$ & Digestive proteinases & $\begin{array}{l}\text { TMMP-2, } 9 \text { positive immunohistochemical staining of } \\
\text { LAM cells [66] }\end{array}$ \\
\hline
\end{tabular}

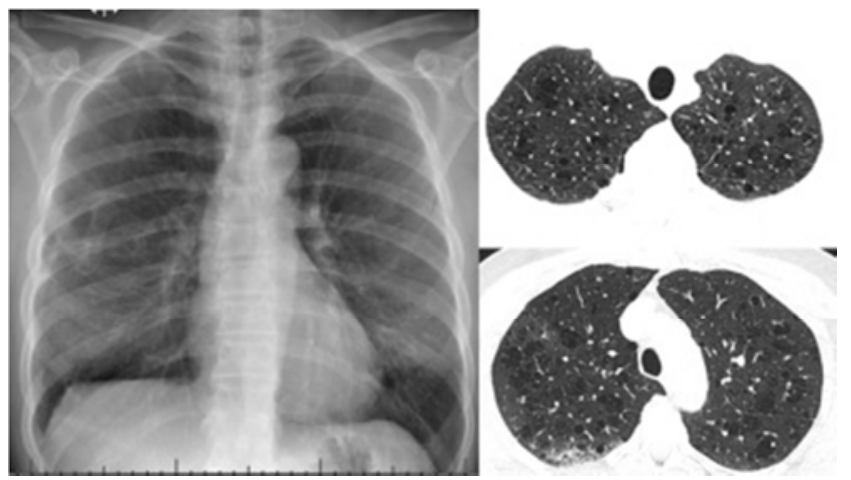

Figure 6. CXR and CT scans in PLAM. CXR on left shows bilateral, diffuse and uniform involvement of lungs. CT scan on right similarly shows this consistently uniform pattern of lung involvement in PLAM.

I have previously proposed viewing the pathogenesis of PLAM using a model of lymphangitic carcinomatosis. [41] There are important manifestations of PLAM that are readily explain by this model of pathogenesis. Retrograde flow of lymphatic fluid through the mediastinal lymphatics into the right and left lungs under even and constant pressure would result in a bilateral and symmetric distribution of LAM cells in the lung. Lymphatic engorgement and microscopic ruptures of pleural lymphatics with extravasation of lymph fluid into the thoracic cavity would explain the common associated finding of chylothorax. Chylothorax occurs in 10$20 \%$ of patients with PLAM. [19] Pneumothorax is found in one third of patients at presentation and occurs in two thirds of patients over the course of the disease. [19] The high incidence of pneumothorax identified in PLAM patient is also readily explained using this model and this will be further explored in the section below addressing the pathogenesis of the cystic transformation of the lung by this disease. To further support the concept of lymphatic spread of LAM to the lungs there is a requirement for obstruction to lymphatic flow at or near the thoracic duct outlet. It is remarkable that in the first reported case of PLAM, that an obstructive lesion of the thoracic duct was identified at autopsy. [5] Subsequent autopsy studies [7, 8, 42] have confirmed the presence of thoracic duct obstructive lesions in this condition, one of which was demonstrated in a dramatic gross photograph [7] (Figure 7). In addition, CT lymphangiographic studies in patients with PLAM and the demonstrated consistent abnormalities and lymphatic drainage including thoracic duct obstructions. [43] Finally, it has been noted that in some cases of PLAM there is a distinct 
histologic lymphatic pattern of infiltration in the lung. [8] Furthermore, evidence of lymphovascular space involvement can be identified in cases of PLAM, even when a distinct lymphangitic pattern of distribution is not histologically prominent. The reason that a lymphatic pattern of LAM cell infiltration is not always histologically prominent is a reflection of the pathogenesis of the cystic transformation of the lung which is discussed in the following section. It is important to note that the obstruction to lymphatic flow at or near the level of the thoracic duct does not need to be complete, only sufficient to lead to retrograde lymphatic flow through the mediastinal lymphatics into the lungs.

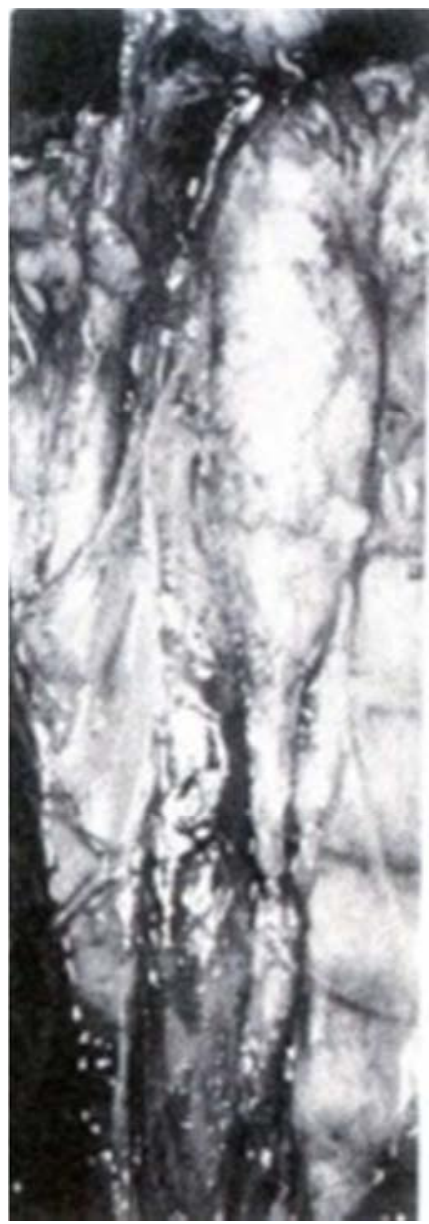

Figure 7. Thoracic duct obstruction in patient with PLAM at autopsy [7] Note the sausage shaped "cast" of the thoracic duct with complete obstruction to lymphatic flow, resulting in retrograde flow of lymphatic fluid into the lungs. The intralymphatic proliferation adds some support to the concept that in LAM there is some limited growth potential that is particularly prominent in intralymphatic spaces, likely due to the high concentration of VEGF and other, as yet undescribed/uncharacterized growth factors. (Permission for reproduction of this photograph granted by Elsevier Limited, Oxford, UK)

\section{The Pathogenesis of Cystic Transformation of the Lung}

Although LAM cells arise in the lung through the lymphatic routes, they do not remain confined to lymphatic spaces. In some cases of PLAM intralymphatic spread of LAM cells can be identified (Figure 8). However, in many cases there is not a distinct lymphatic pattern of distribution. In diseases with a lymphatic distribution in the lung, on histologic examination one sees an accentuation of the disease along the bronchovascular stalks because the lymphatics are situated in this area. In PLAM, on the other hand, the disease looks more randomly distributed throughout the lung without this distinct bronchovascular distribution. There are two reasons for this apparent random distribution of disease. First, when the retrograde flow of lymph fluid flows to the origins of the lymph vessels the LAM cells will deposit in the interstitium in these areas. It is important to note that lymph vessels form from the interstitium of the alveolar spaces and drain towards the hilum of the lung along the bronchovascular stalks in the lung. Thus LAM cells and cell clusters reaching the origin of the lymphatics will reach locations found diffusely throughout the lung and not only along the bronchovascular stalks. LAM cells can then populate alveolar interstitial areas in a diffuse symmetrical and random pattern throughout the lung. Second, investigation of a case of PLAM with chylothorax and with a parietal pleural implant of LAM led to valuable insight into the pathogenesis of the apparent random distribution of this disease in the lung. [41] LAM cells are known to be present in chylous effusions of patients with PLAM. [44] In our reported case, these cells were able to implant and grow in a pattern typical of LAM including an associated lymphatic proliferation in the parietal chest wall pleura tissue. Growth was likely facilitated by the chylous effusion, rich in VEGF and possibly other stimulatory cytokines. The ability of the LAM cells to implant on tissues with subsequent limited growth led to the hypothesis that in the lung, rupture of lymphatics and subsequent extravasation of LAM cells into the surrounding pulmonary parenchyma would lead to random sites of implantation and growth of these LAM cells outside of the location of typical lymphatic routes.

An interesting and perhaps under recognized finding in PLAM is that the metastatic cells not only spread as individual and groups of LAM cells, but may also be accompanied on their passage through the lymphatic channels by their associated lymphatic proliferation. This has been noted in groups of cells identified within chylous pleural effusions [10] and is also apparent in histologic sections (Figure 8).

The cystic transformation of the lungs was originally proposed to be due to a mixture of mechanisms including bronchial obstruction with air trapping and lymphatic obstruction. [8] Histologic evaluation provides no support for either of these proposed mechanisms of cystic transformation of the lungs. There is a significant body of evidence implicating products of the SASP produced by LAM cells in the cystic transformation of the lung. The LAM cells have been demonstrated to produce digestive enzymes TMMP's 2, 9 and cathepsin K. [45, 46] The secretion of these digestive enzymes leads to cystic emphysematous-like digestion of the 
pulmonary parenchymal tissues with cystic transformation of the lungs. Cystic transformation in the regions of the subpleural lymphatics leads to digestion/disruption of the pleura in these cystic areas with subsequent pneumothorax. (Figure 9 summarizes the proposed pathogenesis of PLAM).

Although macroscopic mass lesions do not form in the lungs of patients with PLAM, there is some limited growth potential in LAM cells as there are variably sized microscopic nodules and fascicles of LAM cells in the pulmonary interstitium and the extent of the LAM cell involvement in the lungs has been correlated to prognosis. [47] Furthermore, extrapulmonary LAM lesions in patients with PLAM have been described, and some of these do reach macroscopic sizes. [48] In these, it is noted by the authors that the size of the lesions are "largely determined by the development of multiple cysts containing chylous fluid rather than the degree of proliferation of LAM cells". In addition, as noted above, a macroscopic lesion causing obstruction of the thoracic duct has also been described. [7]

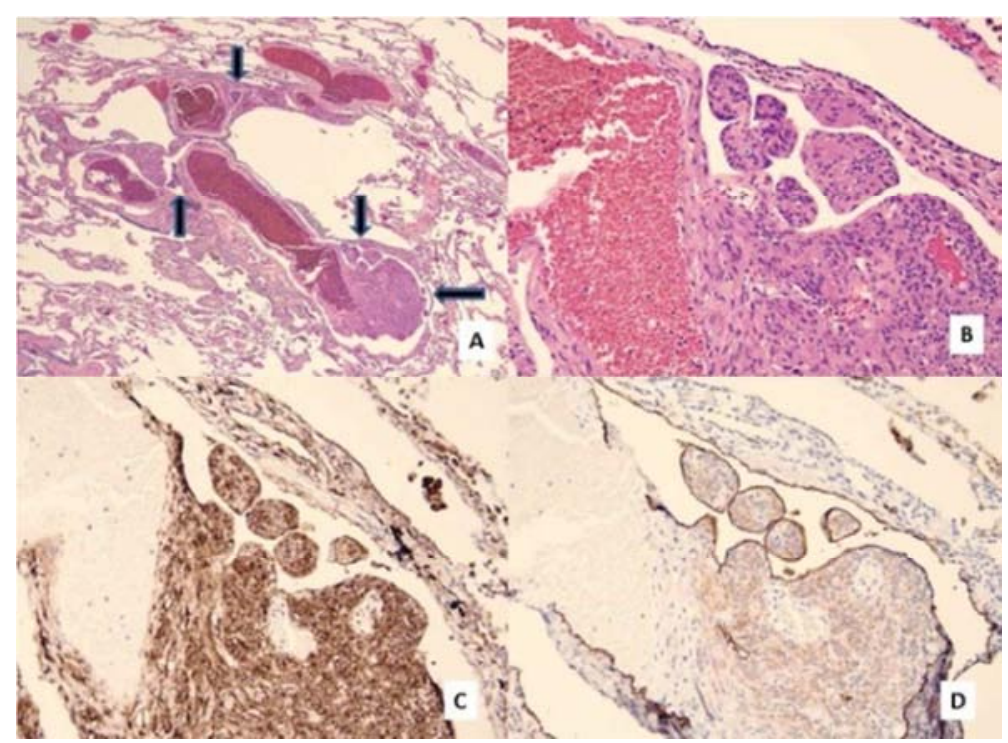

Figure 8. Lymphovascular space involvement in PLAM. (A) Lung with interstitial LAM lesion and associated dilated lymphatic spaces with tumor emboli of LAM (arrows) in lymphatic spaces. (H/E stain, $40 x$ magnification (B) Intralymphatic tumor emboli of LAM. (H/E stain; $200 x$ magnification) (C) Cathepsin K IHC with positive staining of LAM cells. (200x magnification) (D) D2-40 IHC stain with staining of lining of lymphatic space. Also note the positive staining of the tumor emboli with their associated lymphovascular proliferation. (200x magnification)

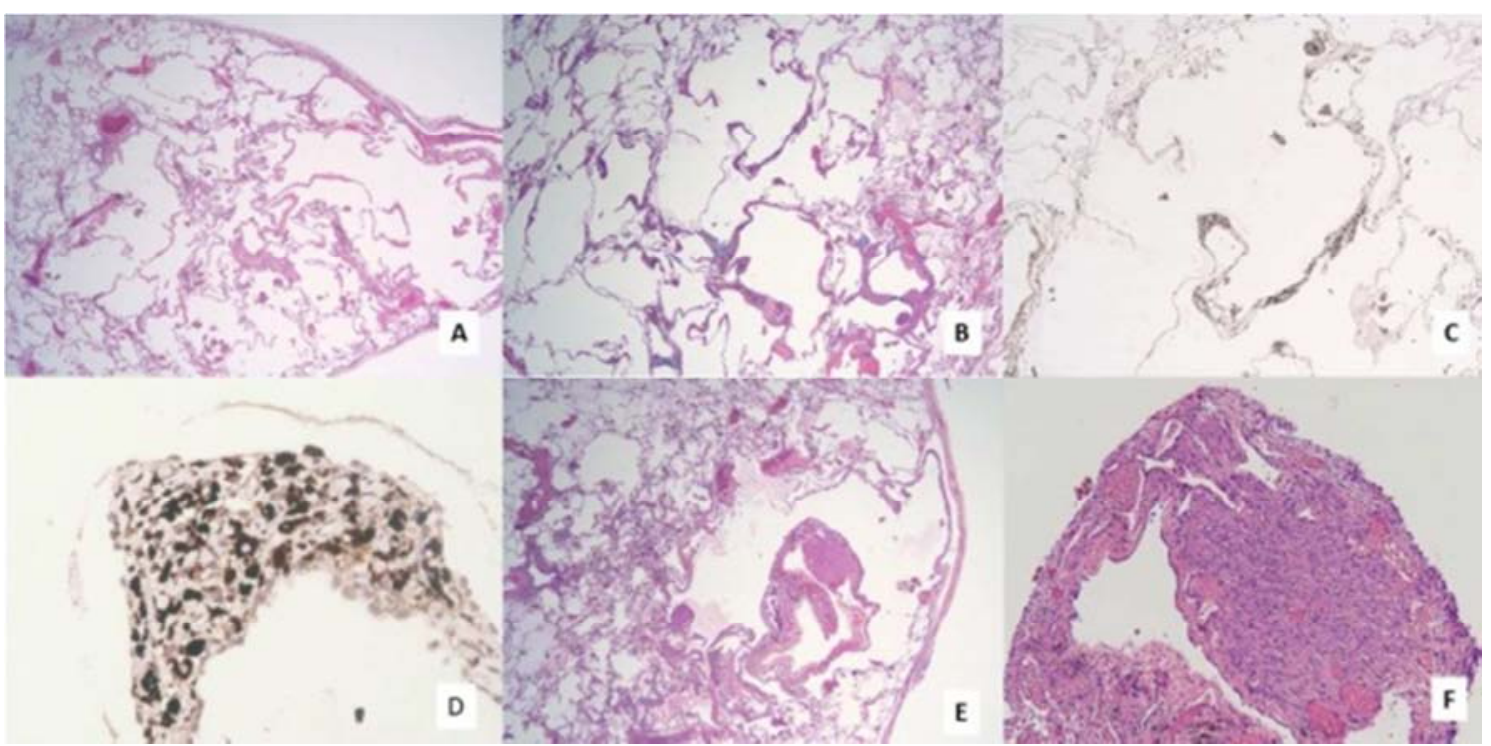

Figure 9. The lung in PLAM. (A) Scanning view of lung in PLAM shows an "emphysema-like" digestion of pulmonary parenchymal tissue with minimal fibrosis and inconspicuous LAM cells. (H/E 20 x magnification) (B) Pulmonary interstitial areas with LAM cells associated with "emphysema-like" digestion of pulmonary parenchymal tissues. This subtle infiltration of the interstitial areas likely results from retrograde extension of LAM cells in lymphatics back to the origins of the lymphatic vessels. (H/E $40 x$ magnification) (C) Cathepsin K IHC stain showing subtle LAM infiltrate in the pulmonary interstitium. (100 $x$ magnification) (D) Cathepsin K IHC stain showing strong positive staining of LAM cells in pulmonary interstitium. (200 x magnification) (E) Subpleural cystic lesion of PLAM. Note the "emphysema-like" digestion of pulmonary parenchymal tissue. There is a distinct nodule of LAM cells in the wall of the cyst. These cystic lesions are prone to rupture leading to the high incidence of pneumothorax in patients with PLAM. (20 x magnification) (F) Microscopic nodule of LAM cells in wall of subpleural cystic lesion of PLAM. (200 x magnification). 


\section{Lymphangioleiomyomatosis (LAM)}

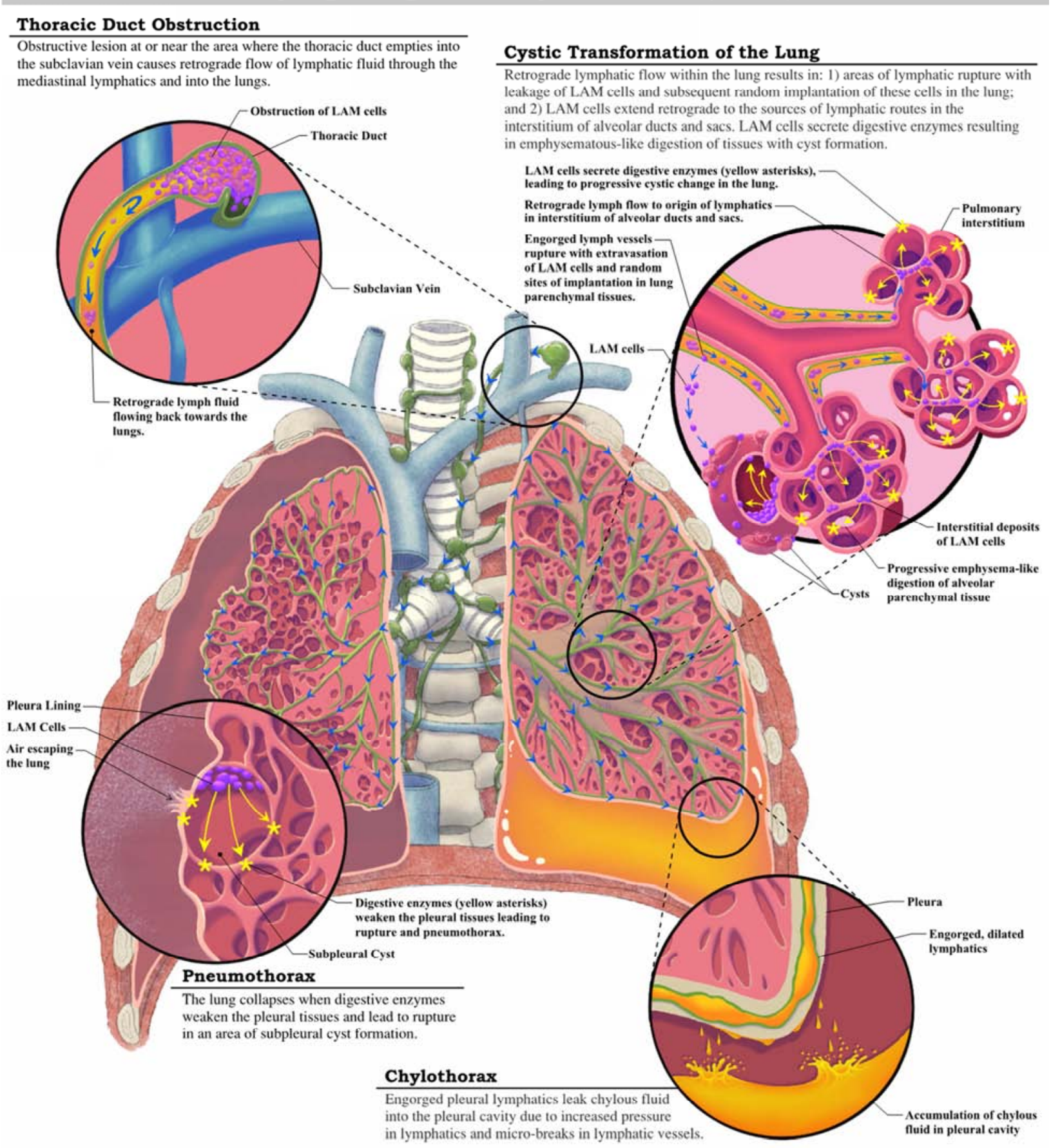

Figure 10. An overview of the pathogenesis of PLAM.

\section{The "PEComa" Concept}

Despite early skepticism,[49] the concept of a precursor perivascular epithelioid cell and a "PEComa" family of tumors has been surprisingly generally accepted and incorporated into the WHO Classifications of tumors of the lung, [50] kidney, [51] and female genital tract. [52] A perivascular epithelioid cell has never been identified.
Alternative well recognized and characterized cells have been proposed as precursor cells for uterine LAM lesions $[11,12]$ and renal AML lesions [53] without resorting to the heretofore undiscovered perivascular epithelioid cell. A possible flaw in the PEComa concept has been the unsupported view that differentiation patterns in tumor cells (i.e. myomelanocytic differentiation) implies a common cell of origin. There are a wide variety of tumors known to produce mucin, for example, and yet, we do not 
think they all have a common precursor cell. Renal AML has cells with the same myomelanocytic differentiation as PLAM, but this is a distinctly different tumor from the Mullerian smooth muscle derived LAM lesions with a distinctly different biologic behavior. A further evaluation of tumors grouped together in the "PEComa" family might better define these distinct tumors and cast further doubt on the notion of a "PEComa family of tumors.

\section{Conclusions}

PLAM is a metastatic lesion. The primary site for this neoplasm is Mullerian smooth muscle tumors with myomelanocytic differentiation located in the female genital tract, predominantly the uterus. The tumor spreads through lymphatics and into the lungs via retrograde lymphatic flow in the mediastinal lymphatics due to obstruction to lymphatic flow at or near the level of the thoracic duct. Progressive pulmonary cystic transformation of the lung is due to the secretion of digestive enzymes by LAM cells resulting in emphysematous-like digestion of the pulmonary tissues. PLAM can be viewed as a state of "neoplastic senescence with limited growth potential" which facilitates understanding of the clinical, radiographic, and pathologic features of this disease.

\section{Acknowledgements}

The author acknowledges Dr. Thomas V. Colby, Lung Path Consultants and Dr. John V. Collin, past president of the American Board of Pathology for review of this manuscript and constructive comments.

The author acknowledges Kelsey Andresen for the graphic art work on Figure 10.

\section{References}

[1] Huie TJ, Olson AL, Schwarz MI FS. Rare interstitial lung diseases. In: Baughman RP, du Bois R, ed. Diffuse Lung Disease: A Practical Approach, Second Edition. second. Springer US; 2012: 293-317.

[2] McCormack FX, Travis WD, Colby T V., Henske EP, Moss J. Lymphangioleiomyomatosis - Calling it what it is: A lowgrade, destructive, metastasizing neoplasm. Am J Respir Crit Care Med. 2012; 186 (12): 1210-1212.

[3] Oprescu N, McCormack FX, Byrnes S, Kinder BW. Clinical predictors of mortality and cause of death in lymphangioleiomyomatosis: A population-based registry. Lung. 2013; 191 (1): 35-42.

[4] Lombard CM. Pulmonary lymphangioleiomyomatosis: A proposed state of neoplastic senescence. Med Hyposthses. 2019; 132 (109372): 1-3.

[5] Burrell L, Ross F. A case of chylous effusion due to leiomyosarcoma. Br J Tuberc. 1937; 31: 38-39.

[6] Vadas G, Pare JAP, D M, Thurlbeck WM, Ch B, Montreal MCP. Pulmonary and Lymph Node Myomatosis. Canad Med
Assoc J 1967; 96: 420-424.

[7] Corrin B, Liebow AA, Friedman PJ. Pulmonary lymphangiomyomatosis: a review. Am J Pathol. 1975; 79 (2): 348-382.

[8] Carrington CB, Cugell DW, Gaensler EA, Marks A, Redding RA, Schaaf JT, et al. Lymphangioleiomyomatosis. Am Rev Resp Dis. 1977; 116: 977-995.

[9] Glasgow CG, Taveira-Dasilva A, Pacheco-Rodriguez G, Steagall WK, Tsukada K, Cai X, et al. Involvement of Lymphatics in Lymphangioleiomyomatosis. Lymphat Res Biol. 2009; 7 (4): 221-228.

[10] Kumasaka T, Seyama K, Mitani K, Souma S, Kashiwagi S, Hebisawa A, et al. Lymphangiogenesis-mediated sheddinq of LAM cell clusters as a mechanism for dissemination in lymphangioleiomyomatosis. Am J Surg Pathol. 2005; 29 (10): 1356-1366.

[11] Hayashi T, Kumasaka T, Mitani K, Terao Y, Watanabe M, Oide T, et al. Prevalence of uterine and adnexal involvement in pulmonary lymphangioleiomyomatosis: A clinicopathologic study of 10 patients. Am J Surg Pathol. 2011; 35 (12): 17761785 .

[12] Lombard CM. Uterine precursor lesions in patients with incidental nodal lymphangioleiomyomatosis: A report of 4 cases. Arch Pathol Clin Res. 2020; 4 (1): 001-004.

[13] Schoolmeester JK, Park KJ. Incidental nodal lymphangioleiomyomatosis is not a harbinger of pulmonary lymphangioleiomyomatosis: A study of 19 cases with evaluation of diagnostic immunohistochemistry. Am J Surg Pathol. 2015; 39 (10): 1404-1410.

[14] 1Kuno I, Yoshida H, Shimizu H, Uehara T, Uno M, Ishikawa $\mathrm{M}$, et al. Incidental lymphangioleiomyomatosis in the lymph nodes of gynecologic surgical specimens. Eur $J$ Obstet Gynecol Reprod Biol. 2018; 231: 93-97.

[15] Rabban JT, Firetag B, Sangoi AR, Post MD, Zaloudek CJ. Incidental pelvic and para-aortic lymph node lymphangioleiomyomatosis detected during surgical staging of pelvic cancer in women without symptomatic pulmonary lymphangioleiomyomatosis or tuberous sclerosis complex. Am J Surg Pathol. 2015; 39 (8): 1015-1025.

[16] Aubry M-C, Myers JL, Ryu JH, Henske EP, Logginidou H, Jalal SM, et al. Pulmonary Lymphangioleiomyomatosis in a Man. Am J Respir Crit Care Med 2000; 162: 749-752.

[17] Mccormack FX, Moss J. S-LAM in a Man? Am J Respir Crit Care Med. 2007; 176: 3-5.

[18] Morgan RJ, Williams DI PJ. Mullerian duct remnants in the male. Brit J Urol. 1979; 51 (6): 488-492.

[19] McCormack FX, Gupta N. Sporadic lymphangioleiomyomatosis: Clinical presentation and diagnostic evaluation. Up To Date. Published 2018. https://www.uptodate.com/contents/sporadiclymphangioleiomyomatosis-clinical-presentation-anddiagnostic-evaluation.

[20] Flum AS, Hamoui N, Said MA, Ximing JY, Casalino DD, McGuire BB, et al. Update on the Diagnosis and Management of Renal Angiomyolipoma. J Urol. 2016; 195 (4P1): 834-846. 
[21] Krymskaya VP, McCormack FX. Lymphangioleiomyomatosis: A Monogenic Model of Malignancy. Annu Rev Med. 2017; 68 (1): 69-83.

[22] Papadopoli D, Boulay K, Kazak L, Pollak M, Mallette FA, Topisirovic I, et al. Mtor as a central regulator of lifespan and aging. F1000Research. 2019; 8: 1-21.

[23] Blagosklonny M V. Cell cycle arrest is not yet senescence, which is not just cell cycle arrest: Terminology for TORdriven aging. Aging (Albany NY). 2012; 4 (3): 159-165.

[24] Wiley CD, Campisi J. From ancient pathways to aging cellsConnecting metabolism and cellular senescence. Cell Metab. 2016; 1013-1021.

[25] Saxton RA, Sabatini DM. mTOR Signaling in Growth, Metabolism, and Disease. Cell 2017; 168 (6): 960-976.

[26] Kim J, Guan KL. mTOR as a central hub of nutrient signalling and cell growth. Nat Cell Biol. 2019; 21 (1): 63-71.

[27] Pal R, Xiong Y, Sardiello M. Abnormal glycogen storage in tuberous sclerosis complex caused by impairment of mTORC1-dependent and -independent signaling pathways. Proc Natl Acad Sci U S A. 2019; 116 (8): 2977-2986.

[28] Blagosklonny M V. Rapamycin, proliferation and geroconversion to senescence. Cell Cycle. 2018; 17 (24): 2655-2665.

[29] Inoki K, Li Y, Xu T, Guan K-L. Rheb GTPase is a direct target of TSC2 GAP activity and regulates mTOR signaling. Genes and Development 2003; 17: 1829-1834.

[30] Lee C-H, Inoki $\mathrm{K}$, Karbowniczek M, Petroulakis E, Sonenberg N, Petri E, et al. Constitutive mTOR activation in TSC mutants sensitizes cells to energy starvation and genomic damage via p53. EMBO 2007; 26: 4812-4823.

[31] Huang J, Manning BD. The TSC1-TSC2 complex: a molecular switchboard controlling cell growth. Biochem J 2008; 412 (2): 179-190.

[32] Yen A SR. Hypophosphorylation of the RB protein in S and G2 as well as G1 during growth arrest. Exo Cell Res. 98; 15 (241) 2: 324-331.

[33] Laplante M, Sabatini DM. mTOR signaling at a glance. J Cell Sci. 2009; 122: 3589-3594.

[34] Coppé J, Desprez P, Krtolica A, Campisi J. The SenescenceAssociated Secretory Phenotype: The Dark Side of Tumor Suppression. Annu Rev Pathol 2010; 5: 99-118.

[35] Hernandez-Segura A, Nehme J, Demaria M. Hallmarks of Cellular Senescence. Trends Cell Biol. 2018; 28 (6): 436-453.

[36] Serrano M. The InflammTORy Powers of Senescence. Trends Cell Biol. 2015; 25 (11): 634-636.

[37] Chen W, Yang S, Abe Y, Li M, Wang Y, Shao J, et al. Novel pycnodysostosis mouse model uncovers cathepsin $\mathrm{K}$ function as a potential regulator of osteoclast apoptosis and senescence. Hum Mol Genet. 2007; 16 (4): 410-423.

[38] Hua Y, Robinson TJ, Cao Y, Shi G-P, Ren J, Nair S. Cathepsin $\mathrm{K}$ knockout alleviatesaging-induced cardiac dysfunction. Aging Cell. 2015; 14 (3): 345-351.

[39] Rapisarda V, Borghesan M, Miguela V, Encheva V, Snijders AP, Lujambio A, et al. Integrin Beta 3 Regulates Cellular
Senescence by Activating the TGF- $\beta$ Pathway. Cell Rep. 2017; 18: $2480-2493$.

[40] Cai X, Pacheco-Rodriguez G, Fan Q-Y, Haughey M, Samsel L, El-Chemaly S, et al. Phenotypic Characterization of Disseminated Cells with TSC2 Loss of Heterozygosity in Patients with Lymphangioleiomyomatosis. Am J Respir Crit Care Med 2010; 182: 1410-1418.

[41] Asao S, Lombard CM, Tsau P. Pulmonary lymphangioleiomyomatosis with parietal pleural involvement: A case report and discussion of pathogenesis using pulmonary lymphangitic carcinomatosis as a model. Hum Pathol Case Reports. 2019; 15: 88-91.

[42] Kumasaka T, Seyama K, Mitani K, Sato T, Souma S, Kondo $\mathrm{T}$, et al. Lymphangiogenesis in lymphangioleiomyomatosis: Its implication in the progression of lymphangioleiomyomatosis. Am J Surg Pathol. 2004; 28 (8): 1007-1016.

[43] Zhang C, Chen X, Wen T, Zhang Q, Huo M, Dong J, et al. Computed tomography lymphangiography findings in 27 cases of lymphangioleiomyomatosis. Acta radiol. 2017; 58 (11): 1342-1348.

[44] Fan D, Ding L, Liu H, Wang J, Ran W, Li Y, et al. Effusion cytology: An effective method for the diagnosis of pulmonary lymphangioleiomyomatosis. J Thorac Dis. 2014; 6 (5): 54-57.

[45] Matsui K, Takeda K, Yu ZX, Travis WD, Moss J, Ferrans VJ. Role for activation of matrix metalloproteinases in the pathogenesis of pulmonary lymphangioleiomyomatosis. Arch Pathol Lab Med. 2000; 124 (2): 267-275.

[46] Chilosi M, Pea M, Martignoni G, Brunelli M, Gobbo S, Poletti V, et al. Cathepsin-k expression in pulmonary lymphangioleiomyomatosis. Mod Pathol. 2009; 22 (2): 161166.

[47] Matsui K, Beasley MB, Nelson WK, Barnes PM, Bechtle J, Falk R, et al. Prognostic significance of pulmonary lymphangioleiomyomatosis histologic score. Am J Surg Path. 2001; 25 (4): 479-484.

[48] Beasley MB, et al. Extrapulmonary lymphangioleiomyomatosis (LAM): Clinicopathologic features in 22 cases. Hum Pathol. 2000; 31 (10): 1242-1248.

[49] Gaffey MJ, Zarbo RJ WL. PEC and sugar. Am J Surg Path. 1992; 16: 308.

[50] Nicholson AG, Henske E TW. PEComatous tumors. In: Travis WD, Brambilla E, Burke AP, Marx A, Nicholson AG, ed. WHO Classification of Tumors of the Lung, Pleura, Thymus and Heart. 4th ed. International agency for research on cancer; 2015: 117-119.

[51] Martignoni G, Cheville J, Fletcher CDM, Pea M, Reuter VE, Ro JY, et al. Angiomyolipoma. In: Moch H, Humphrey PA, Ulbright TM, Reuter VE, ed. WHO Classification of Tumors of the Urinary System and Male Genital Organs. 4th ed. International agency for research on cancer; 2016: 62-66.

[52] Oliva E, Carcangiu ML, Carinelli SG, Ip P, Loening T, Longace TA, et al. Perivascular epithelioid cell tumor. In: Kurman RJ, Carcangiu ML, Herrington S YR, ed. WHO Classification of Tumors of Female Reproductive Organs. 4th ed. International agency for research on cancer; 2014: 146-147. 
[53] Lombard CM. The Pathogenesis of Renal Angiomyolipoma: Alternatives to the Perivascular Epithelioid Cell. 2020; 3 (2): $1-9$.

[54] Freund A, Orjalo A V., Desprez PY, Campisi J. Inflammatory networks during cellular senescence: causes and consequences Trends Mol Med. 2010; 16 (5): 238-246.

[55] Lesma E, Ancona S, Sirchia SM, Orpianesi E, Grande V, Colapeitro P, et al. TSC2 epigenetic defect in primary LAM cells. Evidence of an anchorage-independent survival. J Cell Mol Med 2014; 18 (5): 766-779.

[56] Malaquin N, Martinez A, Rodier F. Keeping the senescence secretome under control: Molecular reins on the senescenceassociated secretory phenotype. Exper Gerontology 2016; 82: $39-49$.

[57] Basisty N, Kale A, Patel S, Campisi J, Schilling B. Expert Review of Proteomics The power of proteomics to monitor senescence-associated secretory phenotypes and beyond: toward clinical applications The power of proteomics to monitor senescence-associated secretory phenotypes and beyond: toward clinical applications. Expert Rev Proteomics 2020; 17: 297-308.

[58] Pacheco-Rodriguez G, Moss J. The role of chemokines in migration of metastatic-like lymphangioleiomyomatosis cells. Crit Rev Immunol. 2010; 30 (4): 387-394.

[59] Valencia JC, Matsui K, Bondy C, Zhou J, Rasmussen A, Cullen K, et al. Distribution and mRNA expression of insulinlike growth factor system in pulmonary lymphangioleiomyomatosis. J Investig Med. 2001; 49 (5): 421-433.

[60] Toledo Do Nascimento EC, Guedes Baldi B, Mariani AW,
Annoni R, Kairalla RA, Pimenta SP, et al Immunohistological features related to functional impairment in lymphangioleiomyomatosis. Respir Research 2018; 19: 8393.

[61] Watz H, Engels K, Loeschke S, Amthor M, Kirsten D, Magnussen H. Lymphangioleiomyomatosis-presence of receptor tyrosine kinases and the angiogenesis factor VEGF-A as potential therapeutic targets. Thorax. 2007; 62 (6): 559.

[62] Radzikowska E, Jagü̈ P, Sobiecka M, ChorostowskaWynimko J, Wiatr E, Kus J, et al. Correlation of serum vascular endothelial growth factor-D concentration with clinical presentation and course of lymphangioleiomyomatosis. Respir Med. 2015; 109 (11): 1469-1475.

[63] Evans SE, Colby TV, Ryu JH LA. Transforming growth factor-b1 and extracellular matrix-associated fibronectin expression in pulmonary lymphangioleiomyomatosis. Chest. 2004; 125 (3): 1063-1070.

[64] Muñoz DP, Yannone SM, Daemen A, Yu S, Vakar-Lopez F, Kawahara $M$, et al. Targetable mechanisms driving immunoevasion of persistent senescent cells link chemotherapyresistant cancer to aging. JCI Insight 2019; 4: e124716.

[65] Osterburg AR, Nelson RL, Yaniv BZ, Foot R, Donica WRF, Nashu MA, et al. NK cell activating receptor ligand expression in lymphangioleiomyomatosis is associated with lung function decline. JCI Insight 2016; 1 (16): 87270.

[66] Hayashi T, Fleming MV, Stetler-Stevenson WG, Liotta LA, Moss J, Ferrans VJ, et. al. Immunohistochemical study of matrix metalloproteinases and their tissue inhibitors in pulmonary lymphangioleiomyomatosis. Hum Pathol 1997; 28 . 1071-1078. 